\title{
Research on Problems and Solutions of Sports Industry Policy System of China
}

\author{
Wang Hanxi
}

Department of Physical Education, Wuhan Institute of Technology, Wuhan, Hubei, China, 430205

hanxi@163.com

Keywords: sports industry policy system, theory of public policy

\begin{abstract}
Sports industry policy has played a great role in promoting the development of sports industry. However, at present, our country has not yet formed unified and perfect sports industry policy system, which restricts the development of sports industry. This paper focuses on sports industry policy system as the research content, analyses the content of our country's sports industry policy system and its problems based on public policy theory, and puts forward countermeasures to solve these problems in order to provide some references for therelated researchers.
\end{abstract}

\section{Concept of Sports Industry Policy System}

According to the academic definition, the sports industry is the sum of all production and operating activities, which is carried out by various social departments and related to sports. The sports industry includes not only departments, which provide social sports service, but also the production departments, which provide physical sports material products.

Sports industry is a variety category and multi-level industry system. The related mechanism has made corresponding policy for this system and each component of it. Sports industry policy refers to the guidelines for action, mated by the country to achieve a certain historical period route of the sports industry. It is a kind of economic policy of state intervention in the development of sports industry. It is also an important basis and means of the national macro leadership, optimization, control and supervision of the sports industry development and operation. These policies together make up the policy system. In conclusion, the sports industry policy system is the sum of all kinds of policies and measures set by the government to promote the formation and development of sports industry.

\section{Main Contents of Sports Industry Policy System}

Sports industry is a multi-class, multi-level and crisscrossed industry system. At present, the national sports industry policy is made up by five categories, including industrial organization policy, industrial structure policy, industrial layout policy, industrial technology policy and other policies, each policy is interrelated and interaction with others which constitute the policy system of the country's sports industry together.

\section{Sports Industry Organization Policy}

Sports industrial organization policy is the sum of a series of economic policies made by the government to coordinate the contradiction between sports industry competition and economies of scale and adjust the relationships between sports enterprises.In our country, there are two kinds of sports industrial organization policy, one is called sports market structure controlling policy, the other one is known as sports market behavior standardization policy. To control the structure of sports market, the government will control the concentration of sports market, the differentiation of products and reduce the import and export trade barriers to achieve its goals. And to standardize market behaviors, the government is mainly in the form of legislation to establish the market rules, and then improve the efficiency of the market, such as the anti-monopoly law, anti-unfair competition law, etc. 


\section{Sports Industry Structure Policy}

Sports industry structure policy refers to the government's intervention in sports industry internal resource allocation process in order to promote the development of industrial structure to the direction of rationalization and upgrading. Rationalization of industrial structure is to adjust industry type, resource allocation to be in accordance with the technical level, consumption structure, basic population quality and resource conditions. Upgrading industrial structure refers to the successive transfer process that the key or the center of gravity of industrial structure transfers from the first industry to the secondary industry and tertiary industry. The upgrading of industrial structure is highly specific reflect in the process of ratio change of various industry departments' output, employment and national income. According to the Chinese Sports Statistics and Related Industry classification standard, our country's sports industry structure policy includes sports competition performance industry, sports fitness leisure industry policy, sports intermediary service industry, sporting goods industry policy and sports construction policy. The core content of sports industry structure policy is to divide sports industry into leading industries, pillar industries and bottleneck industries to determine the key point and orders of industry development.

\section{Sports Industry Layout Policy}

Sports industry policy refers to industry policies that the government uses to plan and intervene the regional distribution of industry. Through adjusting the space layout of the sports industry and giving full play to regional advantage, sports industry policy aims at realizing a comprehensive, coordinated and sustainable development of sports industry. Its main contents include formulating rational and effective regional sports industry policy and choosing regional leading industries. Regional sports industry policies are made in the form of local legislation by the government of all provinces, autonomous regions and municipalities directly under the central government according to the development of sports industry inside its jurisdiction. The selection of region leading sports industry should be based on the current situation of the development of industry, the natural economy condition and the future development potential.

\section{Sports Industry Technology Policy}

Sports industry technology policy refers to the policy combination that the government uses to guide, select, promote and control the technological development of the sports industry. At present, special sports industry technology policy is rare in our country. Sports industrial technology policy in China is mainly manifested in the sports industry technology developing, technical standards, intellectual property rights, technical regulation, technical security, technology planning, etc. Technology standard policy of sports industry in China started late, and now is mainly limited to three levels: open conditions and rating of sports venues and national professional standards. China's sports industry technology development policy mainly includes the development of sports intangible assets and the development and utilization of sports venues. Nowadays, we have begun to focus on intellectual property rights of sports industry, but the related sports industry technology policy develops slowly. Because our country sports industry belongs to the emerging industry, the regulation policy of sports industry is still in the exploratory stage. So far, our country has not yet issued policies relevant to sports industry technology security and technology planning.

\section{Problems of Sports Industry Policy System}

According to the theory of public policy, the sports industry policy system is an organic whole system made up by a series of factors like policy goal, policy subject and object, policy content, policy instruments and policy process.

\section{Obscure Policy Goals}

Reasonable policy goal is a precondition for the smooth development of sports industry. But in our country, sports industry policy goal is not clear. Most sport industry policies havestatement anticipated goals, but the elaboration of the target mostly uses relatively obscure words such as "better" and so on, failing to set up quantitative indicators of the goal. As to validity period of policy, only a minority of sports industry policies has set up the policy deadline, and most of them just set a range. 


\section{Incompetent Policy Object}

As to policy object, it is clear to see that the policy object in China's sports industry policy system is divided into the market main body (enterprises, groups and individuals) and the market environment. The sports enterprises are small, incompetent and lack of leading enterprises and so on. Sports industry has great development prospects and potential, while China has already attached great importance to the sporting goods industry policy, it still needs to intensify the sports industry policy further to vigorously promote the development of leading sports enterprises so as to promote the development of sports industry.

\section{Unbalanced Policy Structure}

In policy structure aspect, there is regional imbalance as well as content imbalance of sports industry. Due to restriction such as factors of economy, society and resource, gap between east and west and urban and rural areas in our country is large, the development of the sports industry in different areas is also affected correspondingly. In the east of China, especially in the coastal and riverside cities, sports industry has developed rapidly and become a hot spot of investment, while in the western region, the sports industry has not yet formed scale, and there is contradiction of structure function between regions. As to industry content, the existing sports industry policy focuses on fitness and sporting goods market, but lacks guidance for other sports industry contents such as sports publicity and infrastructure investment, etc. When developing parts of sports industry, China must attach importance to the coordinated development of the sports policy and pay attention to the relative balance and stability of the industrial structure.

\section{Inadequate Policy Implementation}

As to the policy process, There exist problems like transmission does not reach the designated position and the tracking and evaluation process is absence. The implementation process of sports industry policy system includes policies transmission, policy implementation, policy regulation and effect feedback. There are problems in the transmission and implement processes of present sports industry policy system. In policy transmission, as a result of the fuzziness of sports industry policy content and the diversity of the transmission object (government departments, enterprises, etc.), policy instruction is unclear and policy object exists deviations of policy in understanding. In policy implementation, due to the lack of regulation and the feedback process, it's easy to have a policy to be implemented perfunctorily, expansively and partially.

\section{Countermeasures of Perfecting China's Sports Industry Policy System}

A valid sports industry policy system should have characteristics of consistency, continuity and effectiveness. In particular, the government should perfect the sports industry policy system from the following several aspects.

\section{Quantify Policy Goals}

The goals of the policy guide the direction of policy implementation. When setting policy goals, quantifying the policy objectives of the sports industry policy system such as the deadline of policy implementation, progressive achievements, policy implementation degree and the expected effect is the foundation to realize the policy objectives. The Sports Industry "Twelfth Five-year" Plan put forward thatby the end of the 12th five-year, sports industry added value should be more than 400 billion, this goal is more controllable and binding than goals like that the sports industry output value should rapidly increase. Besides of setting goals, in the process of policy implementation, policy goals are often ambiguous, such as the original designed target is inconsistent with actual conditions, or the goal is too high or too low, the original designed target is limited to a small range, etc., all these needs the adjustment of policy goals of the sports industry policy system.at any time.

\section{Cultivate Policy Objects}

Policy main body should be authoritative, oneness, substantive and representative. In order to avoid the phenomenon of conflicting policies from different departments, policy system of China's sports industry policy main body should insist on the principle of "unified" and clarify the relationships between the policy subjects.In my view, theState General Administration of Sports should be the authority, assisted and coordinatedby other organizations. As to policy object, China 
shall establish and improve the mechanism of the sports market and foster the subject of market. By creating a fair market competition environment, reducing the barriers for enterprises to entry and providing supportive policies and financial support to foster the market competitiveness of leading enterprises. At the same time, China should also cultivate the development mechanism of sports industry and encourage enterprises to increase investment in scientific research in order to promote the sports industry development by leaps and bounds.

\section{Optimize Policy Structure}

The state should pay attention to the balance of the layout of the sports industry.Besides of giving priority to better developed regions of sports industry, the state should also support and encourage the development of sports industry underdeveloped areas with funding and preferential policies.For the development of regional sports industry is not balanced, each region itself should make its industry development goals and development path based on the actual economic and social foundation. In terms of industry content, the state should give priority to the development of sports competition performance industry, regulate the development of sports goods industry, steady the development of sports lottery industry, increase the intensity of the management of public sports facilities, by socializing public sports venues to improve the efficiency of the venues.

\section{Strengthen Policy Implementations}

Sports industry policy system implementation process includes policy transmission, policy implementation, policy regulation and effect feedback. China's sports industry policy implementation process lacks of regulation and feedback of policy effect. To normalize the development of sports industry in the system level, policy subject should strengthen the supervision of the sports industry policy process. By setting up specialized agencies to supervise the process of policy and management and correct the deviation of policy implementation, the state can strengthen restriction and supervision of the power. Besides,by increasing processes of policy feedback, evaluation and revision, China can safeguard the integrity of the sports industry policy system and the implementationof policy.

\section{Conclusion}

The sports industry policy system has a very great significance to the development of sports industry. China's sports industry policy includes industry organization policy, industry structure policy, industry layout policy and industry technology policy. At present, China's sports industry policy system has problems like obscure policy goals, incompetent policy object, unbalanced policy structure, and inadequate policy implementation. We should quantify policy goals, cultivate policy objects, optimize policy structure, and strengthen policy implementations to perfect China's sports industry policy system.

\section{References}

[1] Cao Keqiang,Introduction to Sports Industry, M. Fudan University Press,2004.

[2] Gao Wei, The Research on the Improvement of China's Sport IndustryPolicy System. D, Beijing Normal University, 2014.

[3] Wang Junmin, Research on the System of Sports Industry Policy of China. D,Beijing Sport University, 2014. 